\title{
Curcumin alleviates liver oxidative stress in type 1 diabetic rats
}

\author{
ZHENGLU XIE, BINBIN WU, GUOZHI SHEN, XIAQING LI and QIANYING WU \\ Department of Agriculture and Biotechnology, Jinshan College of Fujian Agriculture \\ and Forestry University, Fuzhou, Fujian 350002, P.R. China
}

Received July 6, 2017; Accepted October 13, 2017

DOI: $10.3892 / \mathrm{mmr} .2017 .7911$

\begin{abstract}
The aim of the present study was to determine the effects of curcumin on antioxidants using a rat model of type 1 diabetes. Seven-week-old male Sprague-Dawley rats were injected with Streptozotocin (STZ) intraperitoneally to induce this model, and then treated with $1.0 \%$ curcumin (weight ratio) mixed in their diet for 21 days. The present study included three groups: Control group (NC), diabetic rat model group (DC) and a curcumin treated group (Diab-Cur). The results demonstrated that curcumin treatment markedly decreased the blood glucose levels, plasma malondialdehyde concentration and plasma activity of glutathione peroxidase (GSH-Px) and catalase (CAT); however, it increased the plasma superoxide dismutase (SOD) and insulin levels. Curcumin treatment increased the expression of the CAT, GSH-Px, HO-1 and norvegicus $N A D(P)$ H quinone dehydrogenase 1 , and decreased the SOD1 expression, which, led to a diminished oxidative stress status. In addition, curcumin treatment significantly increased the protein expression of Keap1 in the Diab-Cur group when compared with the DC group, decreased cytosolic concentrations of Nrf2 while increasing nuclear accumulation of Nrf2. The results provide evidence that oxidative stress in the STZ-induced diabetic rat model may be attenuated by curcumin via the activation of the Keap1-Nrf2-ARE signaling pathway, as evidenced by a decrease in the blood glucose concentration and an increase in the transcription of several antioxidant genes.
\end{abstract}

\section{Introduction}

Diabetes mellitus (DM) is a common endocrine metabolic disorder all over the world (1-3). DM is characterized by chronic inflammation, which can cause oxidative stress and long-term chronic dysfunction (4-8). Previous study has

Correspondence to: Dr Zhenglu Xie, Department of Agriculture and Biotechnology, Jinshan College of Fujian Agriculture and Forestry University, 15 Shangxiadian Road, Fuzhou, Fujian 350002, P.R. China

E-mail: 312498721@qq.com

Key words: curcumin, diabetes mellitus, liver, oxidative stress, Kelch-like ECH-associated protein 1-nuclear transcription factor-like 2-antioxidant response element signal pathway showed that increased ROS production could contribute to the low antioxidative capacity of $\beta$-cells (5). Normally, cells could use the superoxide dismutase (SOD), catalases (CAT), and peroxiredoxins to combat ROS damage. Thus, oxidative stress could be reduced in diabetic mice by increasing SOD production in previous description $(9,10)$. Specifically, the SOD and CAT concentration are regulated by nuclear transcription factor-like 2 (Nrf2), resulting in the inhibition of oxidative stress and lipid accumulation in DM (11).

Curcumin is extensively used in Asian countries, and a wide range of pharmacological properties has been attributed to it (12). Previous studies have reported that curcumin has a number of beneficial effects and used as an antioxidant and anti-inflammatory agent (13-17). Shehzad et al noted the beneficial effects of curcumin on obesity-related-metabolic syndrome (18). Given its beneficial effects, safety and cost-effectiveness, curcumin could be used to treat diabetes and complications $(8,18)$. Moreover, previous studies have reported that curcumin can increase oxygen consumption and the activity of CAT, glutathione peroxidase (GSH-Px) and SOD, decrease lipid levels and protein oxidation to protect against oxidative stress in a high-fat diet induced diabetic rat (15,19-21). GSH-Px, CAT, SOD and HO-1 are important parts of the antioxidant response element (ARE), which is increased by activating Nrf2 $(22,23)$. However, the network of curcumin antioxidant effects resulting from the activation of the Keap1-Nrf2-ARE signaling pathway associated with diabetes has not been completely elucidated. Presented here is an investigation of the capacity of curcumin to inhibit oxidative stress in a rat model of type 1 diabetes by activating the Keapl signaling pathway.

\section{Materials and methods}

Reagents. Streptozotocin and curcumin were purchased from Sigma Company (USA). The kits of blood glucose, GSH-Px, SOD, CAT and malondialdehyde (MDA) were purchased from Nanjing Jiancheng Biologic Project Company (Nanjing, China). The kits of insulin and glucagon radioimmunoassay were procured from North Institute of Biological Technology (Beijing, China).

Animals and ethics statement. Seven-week-old male Sprague-Dawley (SD) rats $(209 \pm 8 \mathrm{~g})$ were obtained from SLAC Laboratory Animal Company (Shanghai, China). After one-week of acclimatization to the laboratory conditions, all 
male SD rats were weighed and randomly assigned. They were fed on standard food pellets and tap water under controlled environmental conditions (temperature: $23 \pm 2{ }^{\circ} \mathrm{C}$ ) and a $12 \mathrm{~h}$ light/dark cycle. All animal experimental procedures were approved by Fujian Agriculture and Forestry University Animal Care and Use Committee. All animal handling procedures were performed in strict accordance with the care of laboratory animals of the Fujian province Zoological Society.

Experimental design. The fifty-four SD rats were divided as follows: group I (NC, $n=18$ ) was a control group, group II (DC, $\mathrm{n}=18$ ) was a diabetes control group, and group III (Diab-Cur, $\mathrm{n}=18$ ) was a normal diet plus $1.0 \%$ curcumin (weight ratio) group. Considered the experiment of the power analysis, a large sample size of 18 per group was used. All animals were fed for 21 days. The rat model of diabetes was established by injecting Streptozotocin (STZ) intraperitoneally at a dose of $80 \mathrm{mg} / \mathrm{kg}$ (24), administered daily for three days. The rats in group I were also injected intraperitoneally with the buffer alone. After treatment, the animals were fasted $12 \mathrm{~h}$ and then the fasting blood glucose levels of all rats were measured. The rats were considered diabetic when the fasting blood glucose levels exceeded $11.1 \mathrm{mmol} / \mathrm{l}$. After 7 days, the rat health was worse than that before and the number of rats that died was from the study (8/18 in Group II and 6/18 in Group III). Thus, we were used the insulin $6 \mathrm{U} / \mathrm{kg}$ treatment once every two day until the end of the experiment but the last time was not used the insulin treatment in order to collected the samples. In order to equal number in rats, the number of rats were excluded from the study (8/18 in Group I and 2/12 in Group III) at the end of experiment.

Blood and tissue collection. During the experiment, blood sample was collected for biochemical measurement every three days starting on day 3. The body weight and food and water intake of each rat were recorded (once every day during the experiment). The animals were fasted $12 \mathrm{~h}$ on the last day, given mild ether anesthesia (1\%, 2 min) and killed by broken neck after collecting the blood sample. The plasma was collected in heparin sodium vessels by centrifugation at $3,500 \mathrm{rpm}$ for $15 \mathrm{~min}$, and was subsequently stored at $-70^{\circ} \mathrm{C}$ until assayed. Tissue samples from heart, liver and leg muscle were immediately collected, weighed, and stored at $-80^{\circ} \mathrm{C}$ until analysis.

Blood analyzed. Blood glucose levels were determined by the glucose oxidase method. The concentrations of MDA and the activities of SOD (cat. no. A001-3), GSH-Px (cat. no. A006-1) and CAT (cat. no. A007-2) were determined using assay kits by spectrophotometrically. All produces were performed according to the manufacturer's instruction.

The concentrations of insulin and glucagon were measured using a radioimmunoassay kit (cat. no. 060514) according to the manufacturer's instructions. The ${ }^{125} \mathrm{I}-\mathrm{Ins}$ (or ${ }^{125} \mathrm{I}-\mathrm{Glu}$ ) and rabbit anti-Ins (or anti-Glu) antibody were mixed with the samples, standards and controls and incubated for $24 \mathrm{~h}$. After centrifuging for $15 \mathrm{~min}$, a separating medium was removed and the sediment was saved for measurement on a $\gamma$-counter.

RNA extraction, cDNA synthesis and qPCR. Liver sample was collected by slaughter and immediately frozen in liquid nitrogen on day 21. RNA was extracted and isolated from liver tissue using TRIzol reagent (TaKaRa, Dalian, China). The concentration of RNA was quantified in a spectrophotometer (Eppendorf-Biotech, Hamburg, Germany) by measuring the absorbance at $260 \mathrm{~nm}$. mRNA expression was measured by qRT-PCR according to our previous study (25) and performed using a MyiQ2 Real-time PCR system (Bio-Rad, Hercules, USA). Primers designed using Primer 5.0 software and synthesized in the Sangon Biotech (Shanghai, China) and listed in Table I.

SDS-PAGE and western blot analysis. The protein was extracted from frozen liver tissue. Cytoplasmic proteins and nuclear proteins were fractionted using a CelLytic ${ }^{\mathrm{TM}}$ NuCLEAR $^{\mathrm{TM}}$ Extraction kit (Sigma-Aldrich Co. LLC, Beijing, China) (26). The protein concentration was measured using the Bradford assay. Subsequently, $50 \mu \mathrm{g}$ protein samples were heated for $10 \mathrm{~min}$ at $98^{\circ} \mathrm{C}$ and subjected to electrophoresis on a $10 \%$ SDS-PAGE gel to separate the proteins. The separated proteins were transferred to nitrocellulose membranes (Bio-Trace, USA) and blocked in 5\% nonfat milk powder for $2 \mathrm{~h}$ at $20^{\circ} \mathrm{C}$. After blocking, the protein was incubated overnight at $4^{\circ} \mathrm{C}$ with anti-keap1 antibody $(1: 1,500$, Abcam) and anti-Nrf2 antibody (1:1,000, Abcam). After washing three times, the corresponding HRP conjugated secondary antibodies were incubated at $4^{\circ} \mathrm{C}$. The anti-GADPH antibody (1:1,000, Abcam) and lamin B (1:1,000, Abcam) was used served as loading controls of cytoplasmic and nuclear fractions, respectively. Finally, blots were washed and detected by enhanced chemiluminescence (ECL) using the LumiGlo substrate (Pierce, USA) and Clarity Western ECL Substrate (BioRad, USA).

Statistical analysis. The statistical significance was analyzed by Tukey's test model of ANOVA (SPSS-20.0 software; IBM Corp., Armonk, NY, USA). P<0.05 was considered to indicate statistical significance. The results were expressed as mean $\pm \mathrm{SE}$.

\section{Results}

Body weight, food and water intake, blood glucose, and plasma insulin and glucogan concentration. After 21 days of the experiment, the body weight $(\mathrm{BW})$ of the rats was significantly reduced in the Diab-Cur group $(\mathrm{P}<0.05)$ and DC group $(\mathrm{P}<0.01)$ compared with the NC group. However, the BW of rats was markedly increased in the Diab-Cur group $(\mathrm{P}<0.05)$ compared to that in the DC group (Fig. 1A). The food and water intake was distinctly increased in the Diab-Cur group compared with NC group (Fig. 1B and C). After the 9th day, curcumin treatment obviously reduced the food intake on days $12(\mathrm{P}<0.05), 15(\mathrm{P}<0.01), 18(\mathrm{P}<0.01)$, and $21(\mathrm{P}<0.01)$, and reduced the water intake on days $12(\mathrm{P}<0.05), 15(\mathrm{P}<0.05)$, $18(\mathrm{P}<0.01)$, and $21(\mathrm{P}<0.01)$ compared with the $\mathrm{DC}$ group.

The concentration of blood glucose was obviously increased in the DC group and Diab-Cur group compared with the NC group (Fig. 1D). After day 9, the blood glucose level was significantly reduced on days $12(\mathrm{P}<0.001), 15(\mathrm{P}<0.001)$, $18(\mathrm{P}<0.01)$, and $21(\mathrm{P}<0.001)$ in the Diab-Cur group. The plasma insulin concentration was markedly decreased $(\mathrm{P}<0.05)$ in the DC and Diab-Cur groups compared with the $\mathrm{NC}$ group, whereas the plasma insulin concentration in the 
Table I. Primers sequence and parameters.

\begin{tabular}{lccccc}
\hline Primers & Genbank number & \multicolumn{1}{c}{ Primer sequence $\left(5^{\prime} \rightarrow 3^{\prime}\right)$} & Orientation & Product $(\mathrm{bp})$ & Annealing temperature $\left({ }^{\circ} \mathrm{C}\right)$ \\
\hline$\beta$-actin & NM_031144.3 & $\begin{array}{l}\text { CACCATGTACCCAGGCATTG } \\
\text { ACAGTCCGCCTAGAAGCATT }\end{array}$ & $\begin{array}{l}\text { Forward } \\
\text { Reverse }\end{array}$ & 229 & 59 \\
CAT & NM_012520.2 & $\begin{array}{l}\text { ACACTTTGACAGAGAGCGGA } \\
\text { TTTCACTGCAAACCCACGAG }\end{array}$ & $\begin{array}{l}\text { Forward } \\
\text { Reverse }\end{array}$ & 220 & 59 \\
GSH-Px & S50336.1 & $\begin{array}{l}\text { GACCGACCCCAAGTACATCA } \\
\text { GCAGGGCTTCTATATCGGGT }\end{array}$ & $\begin{array}{l}\text { Forward } \\
\text { Reverse }\end{array}$ & 155 & 60 \\
HO-1 & NM_012580.2 & $\begin{array}{l}\text { GATGGGTCCTCACACTCAGT } \\
\text { AAGGAAGACACAGGAAGGGG }\end{array}$ & $\begin{array}{l}\text { Forward } \\
\text { Reverse }\end{array}$ & 201 & 59 \\
NQO-1 & NM_017000.3 & $\begin{array}{l}\text { ACCTCTCTGTGGTTTAGGGC } \\
\text { GGACCTGGGTGTGCTATGTA }\end{array}$ & $\begin{array}{l}\text { Forward } \\
\text { Reverse }\end{array}$ & 183 & 59 \\
SOD1 & NM_017050.1 & GCGTCATTCACTTCGAGCAG & Forward & 204 & 50 \\
& & GGTCTCCAACATGCCTCTCT & Reverse & & 5 \\
\hline
\end{tabular}

CAT, catalase; NQO-1, NAD(P)H quinone dehydrogenase 1; GSH-Px, glutathione peroxidase; HO-1, heme oxygenase 1; SOD1, superoxide dismutase 1 .

Table II. Concentrations of hepatic, myocardial and muscular glycogen in type 1 diabetic rats.

\begin{tabular}{lcll}
\hline Group & $\begin{array}{c}\text { Hepatic } \\
(\mathrm{mg} / \mathrm{g})\end{array}$ & $\begin{array}{c}\text { Myocardial } \\
(\mathrm{mg} / \mathrm{g})\end{array}$ & $\begin{array}{c}\text { Muscular } \\
(\mathrm{mg} / \mathrm{g})\end{array}$ \\
\hline $\mathrm{NC}$ & $11.02 \pm 2.42$ & $0.75 \pm 0.18$ & $0.86 \pm 0.39$ \\
DC & $6.02 \pm 2.11^{\mathrm{b}}$ & $0.58 \pm 0.13^{\mathrm{a}}$ & $0.55 \pm 0.21^{\mathrm{a}}$ \\
Diab-Cur & $7.58 \pm 2.87^{\mathrm{a}, \mathrm{d}}$ & $1.23 \pm 0.23^{\mathrm{a}, \mathrm{d}}$ & $0.61 \pm 0.18^{\mathrm{a}, \mathrm{c}}$ \\
\hline
\end{tabular}

Results are from analyses using eighteen rats in each group. Data are presented as the mean \pm standard error. ${ }^{\mathrm{a}} \mathrm{P}<0.05$ and ${ }^{\mathrm{b}} \mathrm{P}<0.01$ vs. $\mathrm{NC}$ group; ${ }^{\mathrm{P}}<0.05$ and ${ }^{\mathrm{d}} \mathrm{P}<0.01$ vs. $\mathrm{DC}$ group. $\mathrm{NC}$, negative control group; DC, diabetic control group; Diab-Cur, treatment group (fed a normal diet plus $1.0 \%$ curcumin).

Diab-Cur group was obviously higher than those in the DC group $(\mathrm{P}<0.05$, Fig. 1E). Furthermore, the plasma glucagon levels were significantly increased in the Diab-Cur group $(\mathrm{P}<0.05)$ and DC group $(\mathrm{P}<0.01)$ compared with those in the NC group rats, but the glucagon levels were significantly reduced $(\mathrm{P}<0.05)$ in the Diab-Cur group compared with the $\mathrm{NC}$ group (Fig. 1F).

Tissue glycogen content. As shown in Table II, the glycogen concentrations of hepatic, myocardial and muscle tissue in the DC group were significantly decreased $(\mathrm{P}<0.05)$ compared with the NC group, whereas the hepatic, myocardial and muscular glycogen levels were significantly increased in the Diab-Cur group $(\mathrm{P}<0.05)$. Although the levels of hepatic and muscular glycogen were obviously decreased in the Diab-Cur group compared with $\mathrm{NC}$ group rats $(\mathrm{P}<0.05)$, the myocardial glycogen levels were significantly increased $(\mathrm{P}<0.05)$.

Plasma SOD, GSH-Px, CAT and MDA level. As shown in Table III, there was an obvious reduction of SOD activity in the
DC group compared with the $\mathrm{NC}$ group $(\mathrm{P}<0.01)$, but curcumin treatment significantly increased SOD activity compared with the levels in both the NC and DC groups $(\mathrm{P}<0.05$ and $\mathrm{P}<0.01$, respectively). Compared to the NC group, the levels of GSH-Px, CAT and MDA in the DC and Diab-Cur groups were significantly increased $(\mathrm{P}<0.05)$. Compared with $\mathrm{DC}$ group, the levels of GSH-Px $(\mathrm{P}<0.01)$, CAT $(\mathrm{P}<0.05)$ and MDA $(\mathrm{P}<0.01)$ were significantly decreased in the Diab-Cur group.

Antioxidase gene expression. As shown in Fig. 2, the results showed that expression levels of the antioxidase genes NAD (P)H quinone dehydrogenase $1(N Q O-1), C A T, G S H-P x$, and $H O-1$ were significantly upregulated in the Diab-Cur group compared with those in the $\mathrm{NC}(\mathrm{P}<0.05)$ and $\mathrm{DC}$ groups $(\mathrm{P}<0.05)$. However, the antioxidase gene expression levels of GSH-PX, HO-l and NQO-1 were markedly downregulated $(\mathrm{P}<0.05)$ in the DC group. Notably, the gene expression of SOD1 was completely contrary to the expression profiles of the other antioxidase genes.

Protein expression. As illustrated in Fig. 3A, compared with the $\mathrm{NC}$ group, the protein expression level of keap1 was significantly upregulated in the Diab-Cur group rats $(\mathrm{P}<0.01)$, but downregulated in the DC group $(\mathrm{P}<0.05)$. Compared with the $\mathrm{DC}$ group, protein expression of keap1 was significantly upregulated in the Diab-Cur group $(\mathrm{P}<0.001)$. As demonstrated in Fig. 3B, curcumin treatment decreased cytosolic concentrations of $\mathrm{Nrf} 2$ while increasing nuclear accumulation of $\mathrm{Nrf} 2$.

\section{Discussion}

STZ-induced type 1 diabetes models are characterized by a loss of $\beta$-cells in the islets of Langerhans in the pancreas, which leads to insulin deficiency and metabolic disease caused by elevated blood sugar $(7,8,27,28)$. In this study, the results showed that BW was markedly decreased and that the blood glucose levels and food and water intake were clearly increased 
Table III. Plasma antioxidant enzyme levels of superoxide dismutase, catalases and glutathione peroxidase and malondialdehyde.

\begin{tabular}{lllll}
\hline Group & SOD $(\mathrm{U} / \mathrm{ml})$ & GSH-Px $(\mathrm{U} / \mathrm{ml})$ & CAT $(\mathrm{U} / \mathrm{ml})$ & $\mathrm{MDA}(\mathrm{nmol} / \mathrm{ml})$ \\
\hline NC & $26.01 \pm 4.47$ & $1,732.40 \pm 73.20$ & $19.03 \pm 3.04$ & $6.03 \pm 1.03$ \\
DC & $20.99 \pm 2.11^{\mathrm{b}}$ & $1,997.88 \pm 65.43^{\mathrm{c}}$ & $27.95 \pm 1.33^{\mathrm{b}}$ & $9.82 \pm 0.67^{\mathrm{c}}$ \\
Diab-Cur & $29.42 \pm 4.43^{\mathrm{a}, \mathrm{e}}$ & $1,882.38 \pm 42.71^{\mathrm{a}, \mathrm{d}}$ & $23.15 \pm 2.29^{\mathrm{a}, \mathrm{d}}$ & $6.87 \pm 0.24^{\mathrm{a}, \mathrm{e}}$ \\
\hline
\end{tabular}

Results are from analyses using eighteen rats in each group. Data are presented as the mean \pm standard error. ${ }^{\mathrm{a}} \mathrm{P}<0.05$, ${ }^{\mathrm{b}} \mathrm{P}<0.01$ and ${ }^{\mathrm{c}} \mathrm{P}<0.001$ mean statistically significant differences when compared with $\mathrm{NC}$ group; ${ }^{\mathrm{P}}<0.05$ and ${ }^{\mathrm{e}} \mathrm{P}<0.01$ vs. DC group. NC, negative control group; $\mathrm{DC}$, diabetic control group; Diab-Cur, treatment group (fed a normal diet plus 1.0\% curcumin); SOD, superoxide dismutase; GSH-Px, glutathione peroxidase; CAT, catalases; MDA, malondialdehyde.
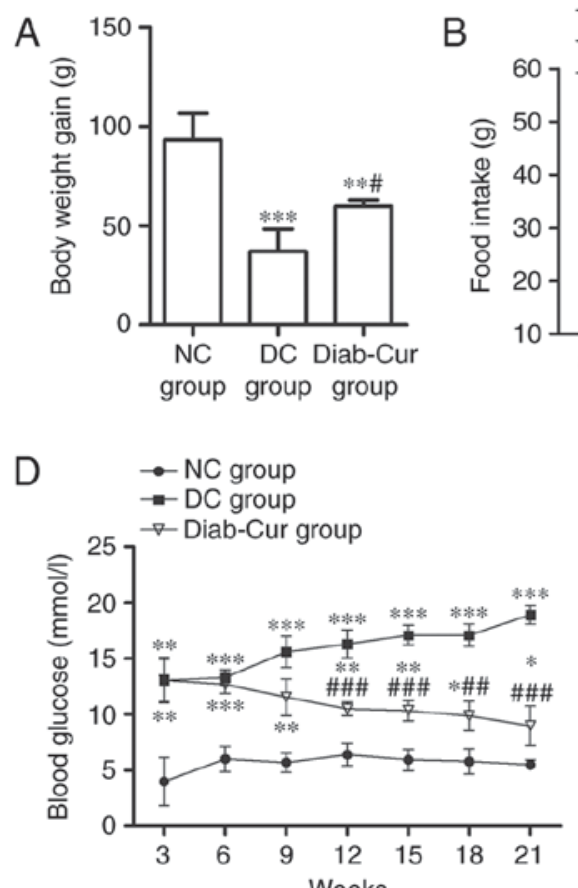

Figure 1. wuuy wergils, ivuu anu watei ins
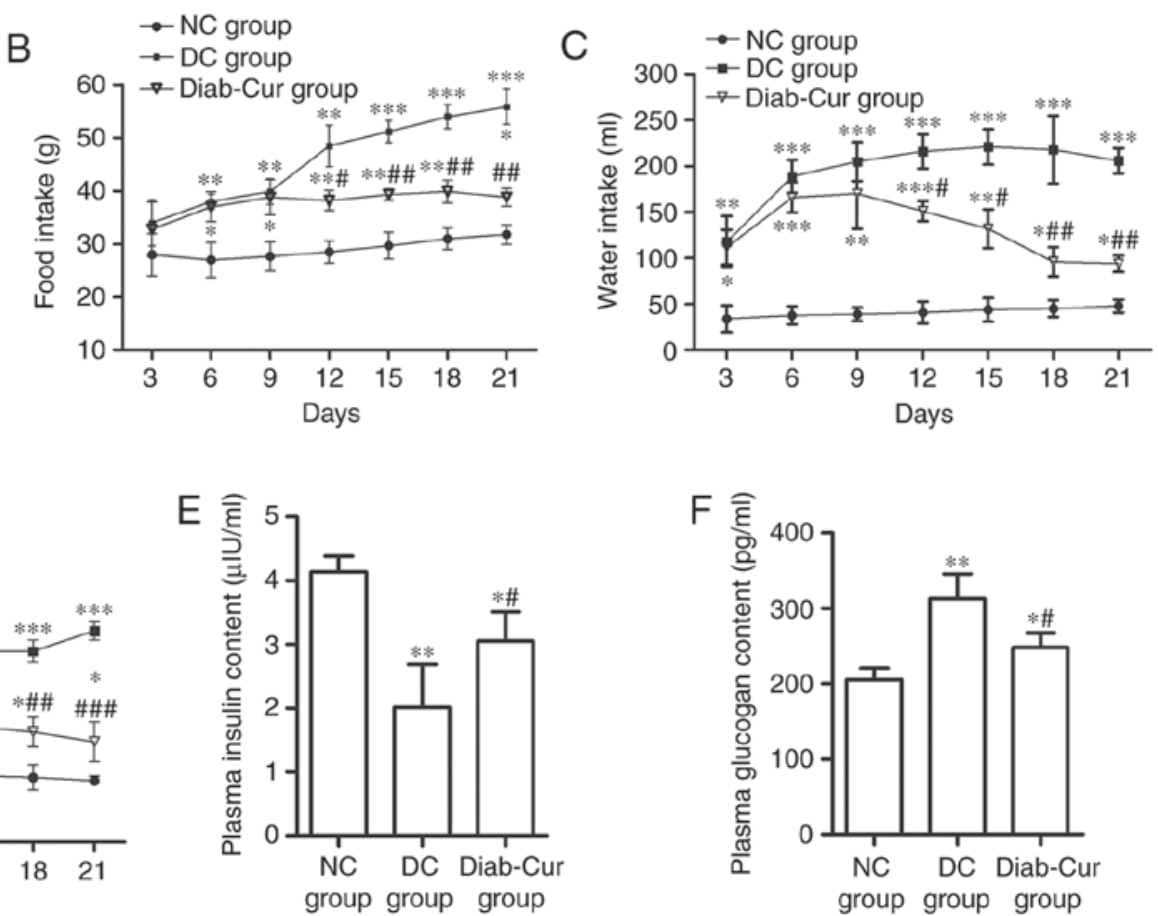
intake; (D) blood glucose concentration; (E) plasma insulin concentration; (F) plasma glucagon concentration. Data are presented as the mean \pm standard error. ${ }^{*} \mathrm{P}<0.05,{ }^{* *} \mathrm{P}<0.01$ and ${ }^{* * *} \mathrm{P}<0.001$ vs. NC group; ${ }^{\#} \mathrm{P}<0.05,{ }^{\# \#} \mathrm{P}<0.01$ and ${ }^{\# \# \#} \mathrm{P}<0.001$ vs. DC group. NC, negative control; DC, diabetic control; Diab-Cur, diabetic with $1.0 \%$ curcumin treatment.

in rat with type 1 diabetes. Especially, the blood glucose levels were elevated more than twofold in the DC group compared with those of control group, whereas curcumin-treated significantly decreased the concentrations of blood glucose (Fig. 1D). Previous studies have shown that curcumin has anti-diabetic activities and that dietary supplements containing curcumin affect glycemic control $(12,29,30)$. Moreover, curcumin supplementation to rat model in diabetes showed that plasma insulin concentration was obviously increased and plasma glucagon levels were markedly reduced (30). In this study, a decrease of $58 \%$ in the level of plasma insulin and an increase of $52 \%$ in the level of plasma glucagon when compared to the control group were observed (Fig. 1E and F). But, curcumin-treated rat model significantly increased plasma insulin levels (Fig. 1E) and decreased plasma glucagon levels (Fig. 1F). At the same time, curcumin treated diabetic animals also showed a significant increase in the hepatic and myocardial glycogen concentrations (Table II). These results imply that curcumin could reduce hyperglycemia.
However, the autoxidation of glucose could increase due to free radicals production with chronic hyperglycemia during the diabetes, which is involved in $\beta$-cell dysfunction $(5,6,27)$. $\beta$-cell dysfunction could lead to $\beta$-cell death, which depends on the subsequent poly (ADP-ribose) synthetase activation and DNA alkylation (5,6,31-33). Moreover, decreases in the expression of antioxidant enzymes and the range of minimum antioxidant competence of $\beta$-cells could lead to free radical damage $(28,34)$. Previous results have demonstrated that the activity of the antioxidant enzymes SOD, CAT and GSH-Px can prevent oxidative stress (35). Importantly, SOD and CAT play important roles in the detoxification of $\mathrm{O}^{2-}(35,36)$. GSH-Px can regulate the intracellular redox system to defend cells against oxidative stress (37). Additionally, through the dismutation and generation of hydrogen peroxide, SOD destroys the superoxide radical, whereas SOD activity is attenuated by catalase or glutathione peroxidase $(36,38,39)$. Recently, reports have shown that pancreatic $\beta$-cells were not damaged by oxidative stress under diabetic conditions by increasing catalase activity $(5,38)$. 


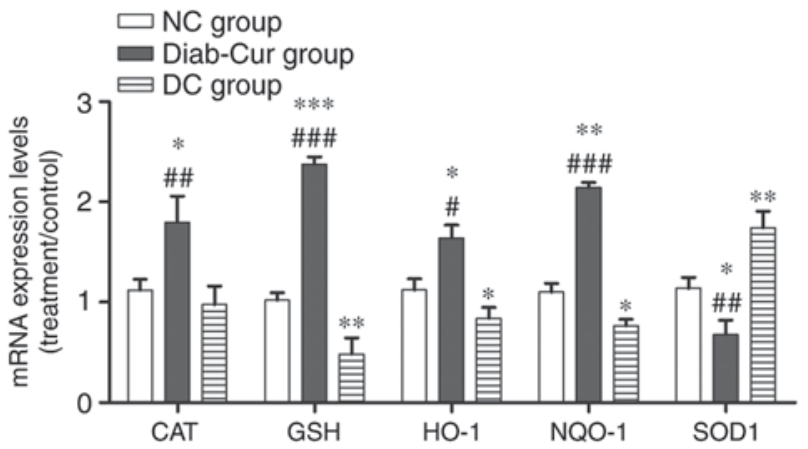

Figure 2. Gene expression of several antioxidant response element-regulated genes. RNA was extracted from the liver, reverse-transcribed to cDNA and analyzed by reverse transcription-quantitative polymerase chain reaction for gene expression. The experiments used 18 samples from each group. Data are presented as the mean \pm standard error. ${ }^{*} \mathrm{P}<0.05,{ }^{* *} \mathrm{P}<0.01$ and ${ }^{* * *} \mathrm{P}<0.001$ vs. NC group; ${ }^{\#} \mathrm{P}<0.05,{ }^{\# \#} \mathrm{P}<0.01$ and ${ }^{\# \# \#} \mathrm{P}<0.001$ vs. DC group. NC, negative control; DC, diabetic control; Diab-Cur, diabetic with $1.0 \%$ curcumin treatment; $\mathrm{HO}-1$, heme oxygenase-1; NQO-1, norvegicus $\mathrm{NAD}(\mathrm{P}) \mathrm{H}$ quinone dehydrogenase 1; GSH-Px, glutathione peroxidase; CAT, catalase; SOD1, superoxide dismutase 1.

A
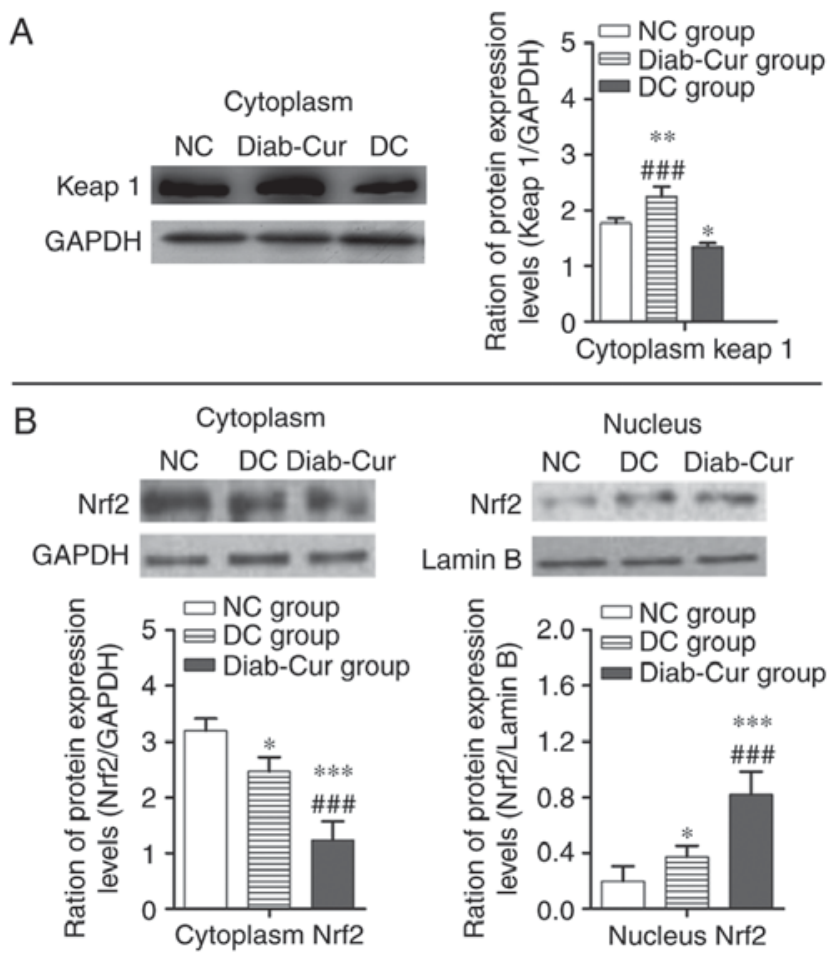

Figure 3. Protein levels of the Keap1-Nrf2-ARE pathway. (A) Keap1 protein; (B) Cytosolic and nucleic Nrf2 levels. The experiments used 18 samples from each group. Data are presented as the mean \pm standard error. ${ }^{*} \mathrm{P}<0.05$, ${ }^{* *} \mathrm{P}<0.01$ and ${ }^{* * * *} \mathrm{P}<0.001$ vs. $\mathrm{NC}$ group; ${ }^{\# \#} \mathrm{P}<0.01$ and ${ }^{\# \# \#} \mathrm{P}<0.001$ vs. DC group. Keap1, Kelch-like ECH-associated protein 1; Nrf2, nuclear factor (erythroid-derived 2)-like 2; NC, negative control; DC, diabetic control; Diab-Cur, diabetic with $1.0 \%$ curcumin treatment.

In the present study, plasma MDA concentration, GSH-Px and CAT activity were significantly increased and indicated that an impairment in antioxidant defenses may increase the scavenging oxygen free radicals $(36,40,41)$ or enhance the antioxidant capacity $(19,20,30)$. In a previous study, activation of the Keap1-Nrf2-ARE pathway was shown to reduce oxidative stress (42). Additional studies have demonstrated that

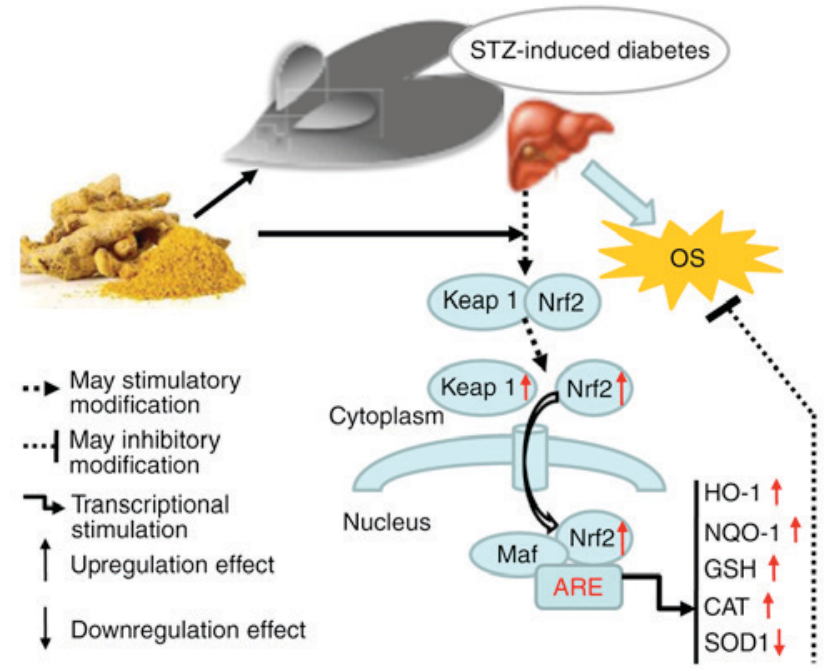

Figure 4. Diagram illustrating the proposed mechanism of action of curcumin. Keap1, Kelch-like ECH-associated protein 1; Nrf2, nuclear factor (erythroid-derived 2)-like 2; HO-1, heme oxygenase-1; NQO-1, norvegicus $\mathrm{NAD}(\mathrm{P}) \mathrm{H}$ quinone dehydrogenase 1; GSH-Px, glutathione peroxidase; CAT, catalase; SOD1, superoxide dismutase 1; Streptozotocin; OS, oxidative stress.

Nrf2 signaling, as activated by salvianolic acid, can be effective against oxidative stress $(22,43-45)$. In the present study, we showed that Nrf2 signaling was activated in curcumin-treated rats. First, the activities of the keap1-Nrf2 complex were reduced, which led to the uncoupling of keap1-Nrf2 in curcumin-treated rats. Second, Nrf2 was stabilized and transported into cell nuclei, leading to the transcription of several ARE-regulated genes (HO-1, NQO-1, GSH-Px, CAT and SODI). Intriguingly, previous studies have shown that upregulating the expression of Nrf2 protein in the nuclear and increased the expression of $\mathrm{HOl}$ and $\mathrm{NQO}-1$ (46). In this study, the expression of the Nrf2 protein and ARE-regulated genes was upregulated in curcumin-treated rats compared to those in the DC group. Importantly, the activation of Nrf 2 by curcumin dramatically relieved oxidative stress in the STZ-induced diabetic rat model.

In conclusion, a diagram illustrating the proposed mechanism of action of curcumin is shown in Fig. 4. We propose that curcumin may be exerts protective effects in STZ-induced diabetes by activating Keap1-Nrf2-ARE signaling through both a decrease in blood glucose concentration and an increase in the transcription of several antioxidant genes.

\section{Acknowledgements}

The present study was supported by the Initial Funding of Jinshan College of Fujian Agriculture and Forestry University (grant no. Z150701); the Natural Science Foundation of Fujian Province (grant no. 2016J01091), and Scientific Research Foundation for Young and Middle-aged Teachers of Fujian Province (grant no. JAT160686).

\section{References}

1. Jiménez-Flores LM, López-Briones S, Macías-Cervantes MH, Ramírez-Emiliano J and Pérez-Vázquez V: A ppargamma, $\mathrm{NF}-\kappa \mathrm{B}$ and AMPK-dependent mechanism may be involved in the beneficial effects of curcumin in the diabetic $\mathrm{db} / \mathrm{db}$ mice liver. Molecules 19: 8289-8302, 2014. 
2. Kume S, Koya D, Uzu T and Maegawa H: Role of nutrient-sensing signals in the pathogenesis of diabetic nephropathy. Biomed Res Int 2014: 315494, 2014

3. Gao Q, Shen W, Qin W, Zheng C, Zhang M, Zeng C, Wang S, Wang J, Zhu X and Liu Z: Treatment of $\mathrm{db} / \mathrm{db}$ diabetic mice with triptolide: A novel therapy for diabetic nephropathy. Nephrol Dial Transplant 25: 3539-3547, 2010.

4. Wang K: Molecular mechanisms of hepatic apoptosis regulated by nuclear factors. Cell Signal 27: 729-738, 2015.

5. Gerber PA and Rutter GA: The role of oxidative stress and hypoxia in pancreatic beta-cell dysfunction in diabetes mellitus. Antioxid Redox Signal 26: 501-518, 2017.

6. Kajimoto $\mathrm{Y}$ and Kaneto H: Role of oxidative stress in pancreatic beta-cell dysfunction. Ann N Y Acad Sci 1011: 168-176, 2004.

7. Maritim AC, Sanders RA and Watkins JB III: Diabetes, oxidative stress, and antioxidants: A review. J Biochem Mol Toxicol 17 24-38, 2003

8. Karunakaran U and Park KG: A systematic review of oxidative stress and safety of antioxidants in diabetes: Focus on islets and their defense. Diabetes Metab J 37: 106-112, 2013.

9. Lieben L: Diabetic nephropathy: Lipid toxicity drives renal disease. Nat Rev Nephrol 13: 194, 2017.

10. Flyvbjerg A: The role of the complement system in diabetic nephropathy. Nat Rev Nephrol 13: 311-318, 2017

11. Nakai K, Fujii H, Kono K, Goto S, Kitazawa R, Kitazawa S, Hirata M, Shinohara M, Fukagawa $M$ and Nishi S: Vitamin o activates the nrf2-keapl antioxidant pathway and ameliorates nephropathy in diabetic rats. Am J Hypertens 27: 586-595, 2014.

12. Hsu CH and Cheng AL: Clinical studies with curcumin. Adv Exp Med Biol 595: 471-480, 2007.

13. Gupta SC, Patchva S, Koh W and Aggarwal BB: Discovery of curcumin, a component of golden spice, and its miraculous biological activities. Clin Exp Pharmacol Physiol 39: 283-299, 2012

14. Shishodia S: Molecular mechanisms of curcumin action: Gene expression. Biofactors 39: 37-55, 2013.

15. Sikora-Polaczek M,Bielak-Zmijewska A and Sikora E: Molecular and cellular mechanisms of curcumin action-beneficial effect on organism. Postepy Bioch 57: 74-84, 2011.

16. Joe B, Vijaykumar M and Lokesh BR: Biological properties of curcumin-cellular and molecular mechanisms of action. Crit Rev Food Sci Nutr 44: 97-111, 2004.

17. Pescosolido N, Giannotti R, Plateroti AM, Pascarella A and Nebbioso M: Curcumin: Therapeutical potential in ophthalmology. Planta Med 80: 249-254, 2014

18. Shehzad A, Ha T, Subhan F and Lee YS: New mechanisms and the anti-inflammatory role of curcumin in obesity and obesity-related metabolic diseases. Eur J Nutr 50: 151-161, 2011.

19. Motterlini R, Foresti R, Bassi R and Green CJ: Curcumin an antioxidant and anti-inflammatory agent, induces heme oxygenase- 1 and protects endothelial cells against oxidative stress. Free Radic Biol Med 28: 1303-1312, 2000.

20. Martínez-Morúa A, Soto-Urquieta MG, Franco-Robles E Zúñiga-Trujillo I, Campos-Cervantes A, Pérez-Vázquez V and Ramírez-Emiliano J: Curcumin decreases oxidative stress in mitochondria isolated from liver and kidneys of high-fat diet-induced obese mice. J Asian Nat Prod Res 15: 905-915, 2013

21. Bhatia NK, Srivastava A, Katyal N, Jain N, Khan MA, Kundu B and Deep S: Curcumin binds to the pre-fibrillar aggregates of cu/zn superoxide dismutase (sod1) and alters its amyloidogenic pathway resulting in reduced cytotoxicity. Biochim Biophys Acta 1854: 426-436, 2015.

22. Zhou J, Qu XD, Li ZY, Wei J, Liu Q, Ma YH and He JJ: Salvianolic acid $\mathrm{b}$ attenuates toxin-induced neuronal damage via nrf2-dependent glial cells-mediated protective activity in Parkinson's disease models. PLoS One 9: e101668, 2014.

23. Zenkov NK, Menshchikova EB and Tkachev VO: Keap1/nrf2/are redox-sensitive signaling system as a pharmacological target. Biochemistry (Mosc) 78: 19-36, 2013.

24. Golalipour MJ, Ghafari S, Kouri V and Kestkar AA: Proliferation of the b-cells of pancreas in diabetic rats treated with urtica dioica. Int J Morphol 28: 399-404, 2010.

25. Xie ZL, Ye PS, Zhang SK, Zhang YS and Shen XZ: Endogenous lps alters liver GH/IGF system gene expression and plasma lipoprotein lipase in goats. Physiol Res 64: 721-729, 2015.

26. Deml B, Kariminejad A, Borujerdi RH, Muheisen S, Reis LM and Semina EV: Mutations in mab2112 result in ocular coloboma, microcornea and cataracts. PLoS Genet 11: e1005002, 2015.

27. Szkudelski T: The mechanism of alloxan and streptozotocin action in B cells of the rat pancreas. Physiol Res 50: 537-546, 2001.
28. Tiedge M, Lortz S, Drinkgern J and Lenzen S: Relation between antioxidant enzyme gene expression and antioxidative defense status of insulin-producing cells. Diabetes 46: 1733-1742, 1997.

29. Yeh GY, Eisenberg DM, Kaptchuk TJ and Phillips RS: Systematic review of herbs and dietary supplements for glycemic control in diabetes. Diabetes Care 26: 1277-1294, 2003.

30. Rahimi HR, Mohammadpour AH, Dastani M, Jaafari MR, Abnous K, Ghayour Mobarhan M and Kazemi Oskuee R: The effect of nano-curcumin on HbA1c, fasting blood glucose and lipid profile in diabetic subjects: A randomized clinical trial. Avicenna J Phytomed 6: 567-577, 2016.

31. Bennett RA and Pegg AE: Alkylation of DNA in rat tissues following administration of streptozotocin. Cancer Res 41: 2786-2790, 1981

32. Vikram A, Tripathi DN, Ramarao P and Jena GB: Evaluation of streptozotocin genotoxicity in rats from different ages using the micronucleus assay. Regul Toxicol Pharmacol 49: 238-244, 2007.

33. Damasceno DC, Volpato GT, Sinzato YK, Lima PH, Souza MS, Iessi IL, Kiss AC, Takaku M, Rudge MV and Calderon IM: Genotoxicity and fetal abnormality in streptozotocin-induced diabetic rats exposed to cigarette smoke prior to and during pregnancy. Exp Clin Endocrinol Diabetes 119: 549-553, 2011.

34. Lenzen S, Drinkgern J and Tiedge M: Low antioxidant enzyme gene expression in pancreatic islets compared with various other mouse tissues. Free Radic Biol Med 20: 463-466, 1996

35. Pigeolet E, Corbisier P, Houbion A, Lambert D, Michiels C, Raes M, Zachary MD and Remacle J: Glutathione peroxidase, superoxide dismutase, and catalase inactivation by peroxides and oxygen derived free radicals. Mech Ageing Dev 51: 283-297, 1990.

36. Meghana K, Sanjeev G and Ramesh B: Curcumin prevents streptozotocin-induced islet damage by scavenging free radicals: A prophylactic and protective role. Eur J Pharmacol 577: 183-191, 2007.

37. Grant CM, MacIver FH and Dawes IW: Glutathione is an essential metabolite required for resistance to oxidative stress in the yeast saccharomyces cerevisiae. Curr Genet 29: 511-515, 1996

38. Jin L, Xue HY, Jin LJ, Li SY and Xu YP: Antioxidant and pancreas-protective effect of aucubin on rats with streptozotocin-induced diabetes. Eur J Pharmacol 582: 162-167, 2008.

39. Liu Z, Li J, Zeng Z, Liu M and Wang M: The antidiabetic effects of cysteinyl metformin, a newly synthesized agent, in alloxanand streptozocin-induced diabetic rats. Chem Biol Interact 173: $68-75,2008$.

40. Afanasiev SA, Kondratieva DS, Rebrova TY, Batalov RE and Popov SV: Coupling of the functional stability of rat myocardium and activity of lipid peroxidation in combined development of postinfarction remodeling and diabetes mellitus. J Diabetes Res 2016: 2548689,2016.

41. He X, de Seymour JV, Sulek K, Qi H, Zhang H, Han TL, Villas-Bôas SG and Baker PN: Maternal hair metabolome analysis identifies a potential marker of lipid peroxidation in gestational diabetes mellitus. Acta Diabetol 53: 119-122, 2016.

42. Shi L, Wu L, Chen Z, Yang J, Chen X, Yu F, Zheng F and Lin X: Mir-141 activates nrf2-dependent antioxidant pathway via down-regulating the expression of keapl conferring the resistance of hepatocellular carcinoma cells to 5-fluorouracil. Cell Physiol Biochem 35: 2333-2348, 2015.

43. Lin M, Zhai X, Wang G, Tian X, Gao D, Shi L, Wu H, Fan Q, Peng J, Liu K and Yao J: Salvianolic acid b protects against acetaminophen hepatotoxicity by inducing nrf 2 and phase II detoxification gene expression via activation of the pi3k and pkc signaling pathways. J Pharmacol Sci 127: 203-210, 2015.

44. Zhang H, Liu YY, Jiang Q, Li KR, Zhao YX, Cao C and Yao J: Salvianolic acid a protects RPE cells against oxidative stress through activation of NRF2/HO-1 signaling. Free Radic Biol Med 69: 219-228, 2014

45. Lee HJ, Seo M and Lee EJ: Salvianolic acid B inhibits atherogenesis of vascular cells through induction of NRF2-dependent heme oxygenase-1. Curr Med Chem 21: 3095-3106, 2014.

46. Suzuki T and Yamamoto M: Molecular basis of the keap1-NRF2 system. Free Radic Biol Med 88: 93-100, 2015.

This work is licensed under a Creative Commons Attribution-NonCommercial-NoDerivatives 4.0 International (CC BY-NC-ND 4.0) License. 